\title{
Procedimento e protótipo computacional para dimensionamento de uma praça de pedágio
}

\author{
[Computational procedure for design and prototype of a toll plaza] \\ Bruno Santana de Faria, Vânia Barcellos Gouvêa Campos* \\ Instituto Militar de Engenharia (IME), Brazil, Instituto Militar de Engenharia (IME), Brazil
}

Submitted 4 Jul 2011; received in revised form 3 Oct 2011; accepted 26 Jan 2012

\begin{abstract}
Resumo
Este artigo propõe um procedimento para o dimensionamento do layout de praças de pedágio como forma de subsidiar a implantação destas praças em novas concessões ou na melhoria das existentes, visando um melhor nível de serviço para o usuário. Para agilizar e facilitar as análises foi desenvolvido um protótipo computacional que define as características da praça de pedágio a partir de um nível de serviço desejado. Para tanto, inicialmente, apresenta-se neste trabalho uma caracterização das praças de pedágio quanto à forma de pagamento da tarifa, a localização da praça no sistema, o layout e seus principais elementos e posteriormente os métodos de dimensionamento. Com base nessas análises, propõe-se um procedimento para dimensionamento de uma praça de pedágio considerando a relação entre as características da praça e o nível de serviço para o usuário.
\end{abstract}

Palavras-Chave: praça de pedágio; concessões; nível de serviço.

\begin{abstract}
This article proposes a procedure for the design of the layout of toll plazas in order to subsidize the implementation of these in new highways concessions or improving existing ones, aiming at a better level of service to the highway user. A computer program prototype was developed for defining the characteristics of the toll plaza from a desired level of service. For that, initially, this article presents a characterization of toll plazas about payment type, location of the plaza in the highway system, the layout and the main elements of design. Based on these analyses, a procedure is proposed for dimensioning toll plazas considering the relationship between toll plazas' characteristics and the desired level-of-service to the highway user.
\end{abstract}

Key words: toll plaza; concessions; service level.

* Corresponding Author. Email: vania@ime.eb.br.

\section{Recommended Citation}

Faria, B. S. and Campos, V. B. G. (2012) Procedimento e protótipo computacional para dimensionamento de uma praça de pedágio. Journal of Transport Literature, vol. 6, n. 4, pp. 38-58.

- JTL/RELIT is a fully electronic, peer-reviewed, open access, international journal focused on emerging transport markets and published by BPTS - Brazilian Transport Planning Society. Website www.transport-literature.org. ISSN 2238-1031.

This paper is downloadable at www.transport-literature.org/open-access. 


\section{Introdução}

Na primeira etapa do programa de concessões federais, que se iniciou em 1995, cerca de $1500 \mathrm{~km}$ de rodovias federais foram concedidos à iniciativa privada (ANTT, 2006a). Além das rodovias federais, mais de $8300 \mathrm{~km}$ de rodovias estaduais também sofreram um processo de licitação para concessão durante o período cerca de 20 anos (ABCR, 2007). Isso representa aproximadamente $6 \%$ dos $160.000 \mathrm{~km}$ de estradas pavimentadas do Brasil. Apesar da porcentagem relativamente pequena, a importância dessas concessões é enorme, já que entre as estradas concedidas estão as principais rodovias do país, que passam pelos grandes centros econômicos do Brasil. As concessionárias, em troca do pedágio, cuidam da conservação e sinalização das rodovias, além de fornecerem outros serviços adicionais previstos nos contratos de concessão (Consumidor Brasil, 2007).

A importância do estudo de praças de pedágio está relacionada à sua capacidade de se tornarem gargalos no fluxo de uma rodovia. Por esse motivo, é importante que o planejamento de uma praça de pedágio seja feito de forma a minimizar, dentre outros fatores, o tempo de espera do usuário, tanto na fila quanto durante o pagamento.

A situação ideal seria existir algum dispositivo eletrônico de cobrança para todos os veículos que utilizassem a rodovia sem que houvesse necessidade de parada. Desta forma, a praça não precisaria existir fisicamente, bastando, apenas, um pórtico onde ficariam os equipamentos que fariam a leitura dos dispositivos nos veículos. Como essa situação, embora ideal, nem sempre é possível, já que poderá haver usuários eventuais da rodovia _como turistas, é importante que a passagem dos veículos pela praça de pedágio seja feita com o melhor nível de serviço possível. Para isso, faz-se necessário a aplicação de uma metodologia que subsidie o dimensionamento e o layout de praças de pedágio visando ao melhor nível de serviço para os usuários.

Outro fator importante a ser considerado é o fato de, com relação à geometria das praças de pedágio, não existe uma formulação para o dimensionamento de seus elementos. O que ocorre é uma padronização desses valores, modificando-se somente o número de cabines em cada praça. Isto gera um problema, visto que cada rodovia possui suas peculiaridades, não podendo 
simplesmente ser feito um projeto aplicável a todas elas. Além disso, essa padronização pode ter como conseqüência indireta a formação de grandes congestionamentos, principalmente nos períodos de grandes feriados e férias escolares. Esses congestionamentos, muitas vezes, vão além da área da praça de pedágio.

Diante desta perspectiva, evidencia-se a necessidade de estudos que contribuam para o dimensionamento adequado das praças, considerando a avaliação do nível de serviço das mesmas, visando a um melhor atendimento ao usuário. Para tanto apresenta-se na segunda seção deste artigo uma caracterização dos elementos de uma praça de pedágio e na terceira seção, metodologias de análise do nível de serviço nas mesmas. Na quarta seção apresenta-se o procedimento desenvolvido para dimensionamento e layout de praças e na quinta seção o protótipo computacional.

\section{Características das praças de pedágio}

Praças de pedágio são áreas projetadas, e estrategicamente localizadas, ao longo de uma rodovia ou em seus acessos, nas quais seus usuários pagam alguma tarifa. Cada praça de pedágio possui características únicas, definidas de acordo com as particularidades do tráfego que por ela passa e do tipo da via na qual é implantada.

Schaufler (1997) define uma praça de pedágio como a área onde o pedágio é cobrado. Esta área começa onde a estrada se alarga o suficiente para que sejam instalados quantos postos de cobrança sejam necessários para o atendimento da demanda do tráfego, continua pelas ilhas de cobrança e termina onde a rodovia volta à sua largura original.

A composição das praças de pedágio se diferencia em função das características de sua operação que incluem: (i) a forma de cobrança, (ii) a localização dentro do sistema viário e (iii) do próprio layout. A seguir são descritas estas características e condicionantes operacionais. 


\subsection{Métodos de cobrança}

Existem três tipos de cobrança de pedágio: manual, automática e eletrônica. A escolha da forma de pagamento por parte do usuário depende, dentre outros fatores, da freqüência em que é utilizada a rodovia.

A cobrança manual requer um arrecadador na cabine e, em algumas situações excepcionais, um arrecadador volante, por exemplo, quando as filas de espera ultrapassam os limites físicos da praça. De acordo com a classificação do veículo, uma determinada tarifa é cobrada. O arrecadador recebe, além do pagamento em espécie, cupons comprados dos arrecadadores volantes e vale-pedágio, sendo este usualmente utilizado por caminhões.

A cobrança automática consiste no pagamento da tarifa em máquinas automáticas de moedas e o usuário, em vez de interagir com o arrecadador, insere quantas moedas sejam necessárias para efetuar o pagamento.

A cobrança eletrônica (conhecida também como ETC - electronic toll collection, ou AVI automatic vehicle identification) é um sistema em que uma antena identifica o veículo equipado com uma etiqueta ou com um transponder, também conhecido como tag, quando este se aproxima da praça. Desta forma, o sistema debita o valor da tarifa correspondente ao veículo. A cobrança eletrônica de pedágio aumenta a capacidade de atendimento da praça, já que os veículos não precisam parar para efetuar o pagamento.

\subsection{Características de localização}

Rastorfer (2004) classifica as praças de pedágio, em função da localização no sistema viário, em dois tipos: o tipo "bloqueio" e o tipo "barreira".

No pedágio de bloqueio, os motoristas recebem um ticket nos pontos de entrada da rodovia, e efetuam o pagamento da tarifa nos pontos de saída. O ticket identifica a extensão do trecho percorrido, que é utilizada para a cobrança da tarifa em conjunto com a classificação do veículo. Geralmente, essas rodovias são "fechadas”, ou seja, todos os veículos pagam algum valor de tarifa. 
No pedágio de barreira, a tarifa é cobrada somente em função da classificação do veículo. Podem ser "abertos" ou "fechados". São "fechados" quando há praças principais ao longo da rodovia, e quando há, também, cabines nas rampas de acesso à rodovia de tal forma que todos paguem a tarifa. Nos sistemas "abertos", alguns usuários trafegam gratuitamente pela rodovia entre alguns acessos.

\subsection{Layout}

Os elementos de projeto do layout de uma praça de pedágio dizem respeito principalmente a duas regiões específicas: a zona de aproximação e a zona de afastamento (Figura 1). Smith (2006), em um estudo sobre o estado-da-arte das praças de pedágio em rodovias norteamericanas, explica cada uma dessas regiões.

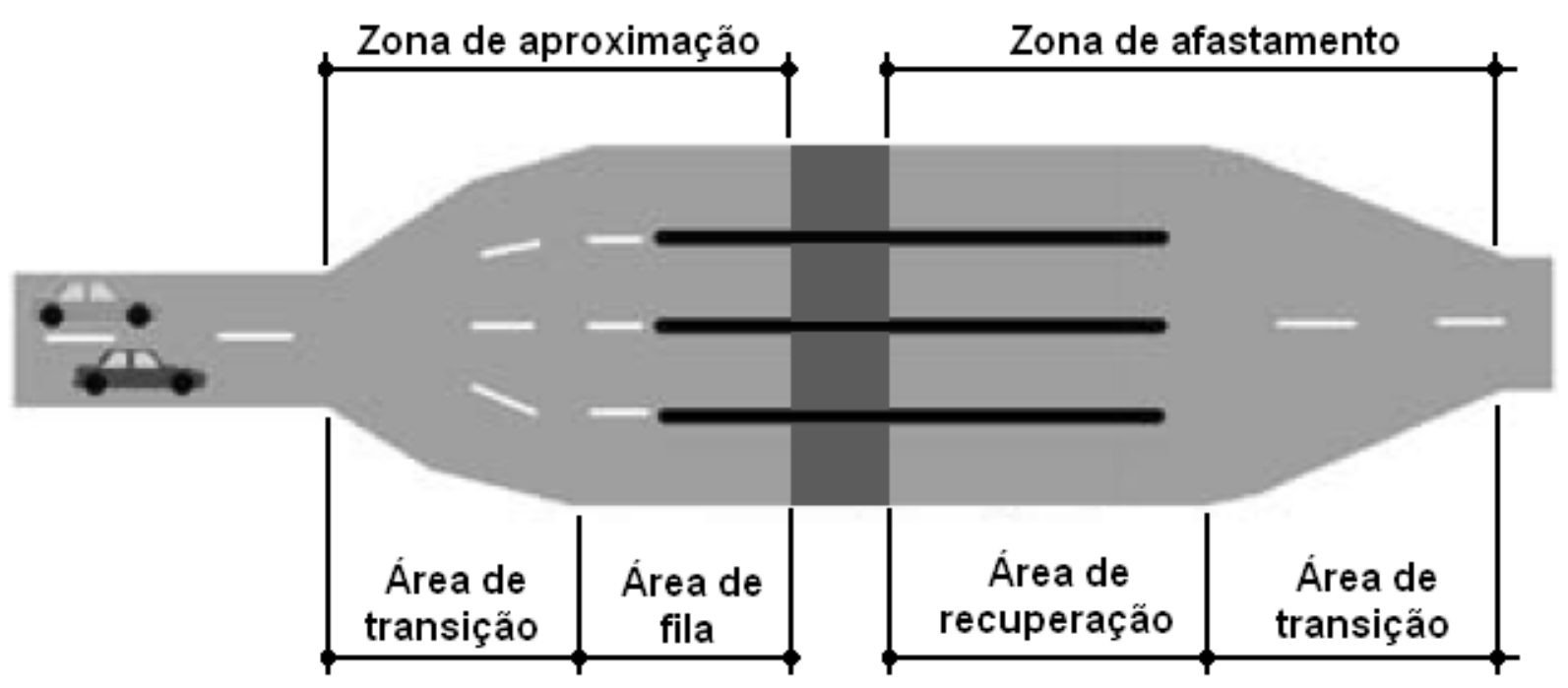

Figura 1: Desenho esquemático de uma praça de pedágio

A zona de aproximação é a região da praça de pedágio localizada antes das cabines de cobrança. É dividida em área de transição e área de filas. A área de transição é o trecho em que a rodovia se alarga até atingir uma largura suficiente para abrigar todas as cabines de cobrança. A área de filas é o trecho de largura constante entre a área de transição e as cabines.

Após as cabines de cobrança, a rodovia precisa voltar à largura original. A zona de afastamento inclui a área de recuperação, que é uma área de largura constante usada para que os motoristas possam acelerar seus veículos sem que haja interferência de veículos em outras faixas; e a área de transição onde o pavimento volta à largura original. O modo pelo qual essa 
transição ocorre varia de acordo com a rodovia e é um ponto crucial no que diz respeito ao nível de serviço.

\section{Análise do nível de serviço}

A análise do nível de serviço em sistemas de transporte se faz cada vez mais necessária na medida em que este fator serve para avaliar o desempenho do sistema e de mudanças implantadas. No Brasil, existe uma preocupação em relação ao desempenho de praças de pedágio, principalmente por estas fazerem parte de um sistema concessionado e que precisa ser fiscalizado visando o bom atendimento ao usuário. Como subsídio a uma análise do nível de serviço em praças de pedágio, desenvolveu-se um estudo sobre as metodologias utilizadas, após esta análise duas metodologias foram consideradas para o desenvolvimento do procedimento desenvolvido neste trabalho: Araújo (2001) no Brasil, e Klodzinski \& Al-Deek (2002) nos Estados Unidos. Outros processos podem ser encontrados no estudo desenvolvido por Faria (2008) e Oliveira (2009).

\subsection{Metodologia utilizada por Klodzinski and Al-Deek (2002)}

Motivados pelo fato de o Highway Capacity Manual (HCM) não possuir uma escala de nível de serviço aplicada especificamente a praças de pedágio, KLODZINSKI \& AL-DEEK (2002) elaboraram uma escala com base em estudos realizados em praças de pedágio de várias rodovias da Flórida, nos Estados Unidos.

Para determinar a escala de nível de serviço, foi assumido que o nível de serviço mais alto para o usuário corresponde a não esperar na fila. Com isso, o único tempo gasto na praça de pedágio é o tempo de atendimento. Esse é o nível de serviço "A" para a nova escala. Pesquisas indicaram que o tempo de atendimento médio é de aproximadamente 14 segundos. Definido o nível de serviço A, o restante da escala é definido com aumentos percentuais, tal qual a escala do HCM para interseções semaforizadas, conforme apresentado na Tabela 1. 
Tabela 1: Escala de Nível de Serviço proposta por Klodzinski and Al-Deek (2002)

\begin{tabular}{cc}
\hline Nível de Serviço & Tempo médio no sistema(s) \\
\hline A & $\leq 14$ \\
B & $14<\mathrm{W} \leq 28$ \\
C & $28<\mathrm{W} \leq 49$ \\
D & $49<\mathrm{W} \leq 77$ \\
E & $77<\mathrm{W} \leq 112$ \\
F & $\mathrm{W}>112$ \\
\hline Fonte: Klodzinski \& Al-Deek (2002)
\end{tabular}

\subsection{Metodologia de Araújo (2001)}

Araújo (2001) sugeriu uma escala de nível de serviço (Tabela 2) baseada em estudos realizados em rodovias no estado de São Paulo. A autora, utilizando um modelo de simulação, estabeleceu que a capacidade de uma praça de pedágio corresponde ao fluxo de veículos no qual as filas se limitam à área da praça. Os outros limites da escala de nível de serviço foram determinados em função do tempo médio no sistema. O nível $\mathrm{A}$, por exemplo, foi estabelecido considerando o tempo no sistema inferior ao tempo de atendimento mais metade do tempo de atendimento de outro veículo, isto é, menos de um veículo, em média, na fila.

Tabela 2: Escala de nível de serviço proposta por ARAÚJO (2001)

\begin{tabular}{ccc}
\hline Nível de Serviço & Tempo médio no sistema (s) & Fila média (veic) \\
\hline A & $\leq 40$ & $\leq 1$ \\
B & $\leq 60$ & $\leq 2$ \\
C & $\leq 90$ & $\leq 3$ \\
D & $\leq 120$ & $\leq 4$ \\
E & $\leq 650$ & $\leq 30$ \\
F & $>650$ & $>30$ \\
\hline
\end{tabular}

Segundo Oliveira (2003), o tamanho da fila influencia o tempo de atendimento e, conseqüentemente, o tempo médio no sistema. Este fato foi observado numa pesquisa realizada numa praça de pedágio da rodovia RS-40. Assim, pesquisas em outras praças podem futuramente estabelecer um padrão de comportamento que subsidie uma melhor definição do tempo de atendimento com pagamento manual. 


\section{Formulação do procedimento}

O procedimento proposto tem por objetivo calcular os elementos de uma praça de pedágio: zona de aproximação e zona de afastamento a partir de um nível de serviço esperado. Para isto, são consideradas três macro etapas.

Na primeira etapa define-se o nível de serviço esperado para a praça de pedágio; a seguir, determina-se o número de cabines necessário para se ter uma operação compatível com o nível de serviço definido. Posteriormente com o número de cabines e as características da via definem-se os elementos de layout (zonas de aproximação e de afastamento).

Para tanto, são utilizados, como subsídio, o método para dimensionamento do número de cabines proposto por Tiefensee (2005) e os valores propostos por Schaufler (1997) e por McDonald \& Stammer (2001) para as zonas de aproximação e de afastamento.

\subsection{Definição do nível de serviço}

Para se definir o nível de serviço, propõe-se uma escala de nível de serviço que se baseia nos estudos desenvolvido por Araújo (2001) e Klodzinski \& Al-Deek (2002). Para a elaboração da escala, Araújo (2001) procurou definir o limite superior de sua escala de nível de serviço, referente ao nível de serviço E, ou seja, a capacidade da praça. No entanto, como existe uma grande diferença entre o nível E e o nível D quando se analisa o tempo no sistema (de 120 para 650 segundos) e o número médio de veículos na fila (de 4 para 30 veículos), considerouse conveniente criar uma nova escala para medir o desempenho da praça.

Assim, a escala proposta tem como base o limite superior do nível de serviço A proposto por Araújo (2001). Os demais valores da escala serão definidos de acordo com o critério de Klodzinski \& Al-Deek (2002). Esse critério corresponde ao aumento percentual utilizado pelo Highway Capacity Manual (2000) na escala de nível de serviço para interseções semaforizadas. Na referida escala, os aumentos são de $100 \%$ de A para B, 75\% de B para C, $57,14 \%$ de $C$ para $\mathrm{D}$ e de $45,45 \%$ de D para $\mathrm{E}$.

Desta forma, associando-se as propostas de por Araújo (2001) e Klodzinski \& Al-Deek (2002), foi definida a escala de nível de serviço para tempo no sistema. Para a fila média, foi 
feita uma relação entre os valores de tempo no sistema e a fila média da escala proposta por Araújo (2001) e após o ajuste de uma curva do tipo $y=a \cdot x^{b}$, foram calculados os valores da escala de nível de serviço para a fila média, conforme apresenta a Tabela 3.

Tabela 3: Escala proposta de nível de serviço

\begin{tabular}{ccc}
\hline Nível de serviço & Tempo no sistema (s) & Fila média (veic) \\
\hline A & $\leq 40$ & $\leq 1$ \\
B & $\leq 80$ & $\leq 2,5$ \\
C & $\leq 140$ & $\leq 5$ \\
D & $\leq 220$ & $\leq 8,5$ \\
E & $\leq 320$ & $\leq 13$ \\
F & $>320$ & $>13$ \\
\hline
\end{tabular}

Fonte: Faria (2008)

\subsection{Número de cabines}

Para definição do número de cabines, são necessárias as seguintes informações:

- Volume de tráfego esperado na hora de pico;

- Porcentagem dos veículos que efetuam pagamento manual;

- Porcentagem dos veículos que efetuam pagamento eletrônico;

- Taxa de atendimento das cabines manuais;

- Taxa de atendimento nas faixas com cobrança eletrônica;

A partir destes dados, o número de cabines é determinado segundo o procedimento proposto por Tiefensee (2005). Este procedimento, apresentado no fluxograma da Figura 2, servirá de subsídio para o cálculo dos elementos restantes. 


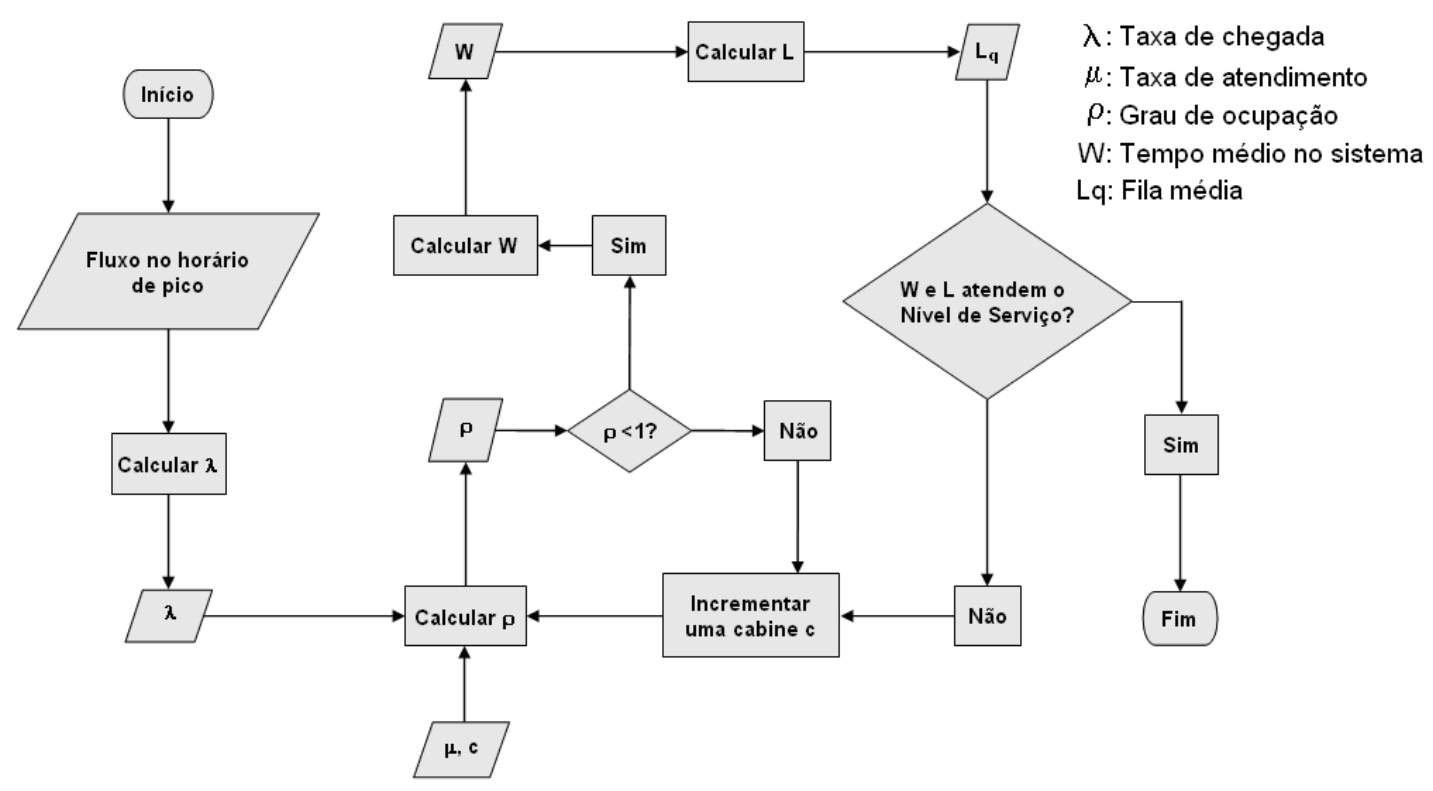

Figura 2: Dimensionamento do número de cabines

Fonte: Adaptado de Tiefensee (2005)

\subsection{Elementos de layout: Zonas de aproximação e de afastamento}

O primeiro passo para o dimensionamento compreende o cálculo do comprimento da área de filas, o número de transições e o offset. Após isso, calcula-se o comprimento de cada transição. No passo seguinte determinam-se os comprimentos das áreas de transição e de recuperação. Com esses valores, conclui-se o cálculo dos elementos das zonas de aproximação e de afastamento. A Figura 3 apresenta um fluxograma que explica melhor a seqüência de cálculos. 


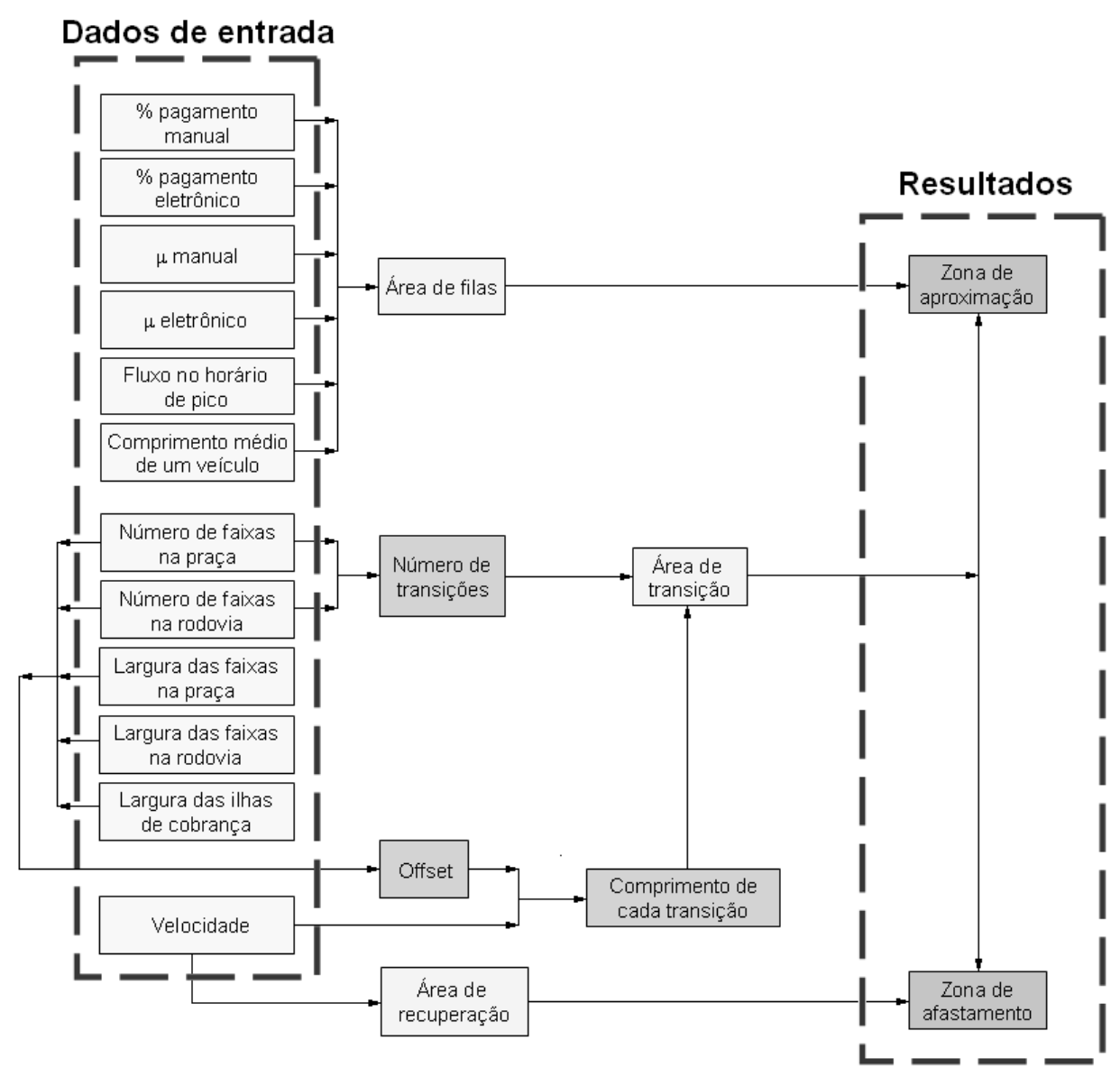

Figura 3: Fluxograma para dimensionamento dos elementos de layout

Fonte: Faria (2008)

\subsubsection{Zona de aproximação}

O comprimento da zona de aproximação pode ser calculado de duas formas. Na primeira delas utiliza-se toda a zona de aproximação para as filas criadas em situações normais. Desta forma, em situações excepcionais as filas se estenderiam além dos limites da praça. A outra forma é dimensionar a área de filas para comportar as filas em situações normais. Com isso, a área de transição seria usada somente em situações atípicas de tráfego na rodovia. $\mathrm{O}$ procedimento proposto neste artigo será baseado na segunda forma de dimensionamento.

Alguns autores propõem valores para os comprimentos da zona de aproximação baseados exclusivamente na velocidade de aproximação da praça. Dependendo do número de cabines a serem implantadas, esse comprimento pode ser insuficiente, já que o taper - ou seja, a taxa de 
alargamento da praça - poderia atingir valores muito baixos. Isso poderia provocar obstruções nas faixas mais laterais da praça. Conseqüentemente, é necessário considerar o número de cabines existentes na praça de pedágio para um dimensionamento adequado. Schaufler (1997) e McDonald \& Stammer (2001) propõem valores para o taper da zona de aproximação. Esses valores podem ser função somente da velocidade, já que o taper, multiplicado pelo offset, fornece o comprimento necessário para a zona de aproximação. O offset é o quanto a rodovia precisa alargar para que se consiga implantar o número necessário de faixas para a cobrança de pedágio.

Além disso, Schaufler (1997) apresenta valores mínimos para o comprimento da área de transição, conforme apresentados na Tabela 4.

Tabela 4: Comprimento mínimo da área de transição

\begin{tabular}{cccc}
\hline $\begin{array}{c}\text { Velocidade de } \\
\text { projeto }(\mathrm{km} / \mathrm{h})\end{array}$ & $\begin{array}{c}\text { Velocidade de } \\
\text { aproximação }(\mathrm{km} / \mathrm{h})\end{array}$ & Taper & $\begin{array}{c}\text { Comprimento mínimo da } \\
\text { área de transição }(\mathrm{m})\end{array}$ \\
\hline 80 & 70 & $5,5: 1$ & 137 \\
88 & 75 & $6,0: 1$ & 168 \\
96 & 82 & $6,5: 1$ & 198 \\
104 & 88 & $7,0: 1$ & 229 \\
112 & 93 & $7,5: 1$ & 259 \\
\hline \multicolumn{4}{c}{ Fonte: Schaufler $(1997)$}
\end{tabular}

McDonald \& Stammer (2001) realizaram um levantamento de rodovias, pontes e túneis pedagiados nos Estados Unidos. Os autores coletaram informações a respeito dos tapers utilizados nas zonas de aproximação das praças de pedágio destas estruturas. A partir desses valores, os autores propuseram uma formulação analítica para o cálculo do comprimento da área de transição dentro da zona de aproximação. Essa formulação considera a velocidade de aproximação e o offset da praça.

O valor do offset depende do padrão de aproximação (ou de afastamento) da praça. Se a praça é alargada somente para o lado direito ou somente para o lado esquerdo, o offset é a diferença entre a largura da praça e a largura da rodovia. No entanto, se a praça é alargada para ambos os lados, o offset é a metade da diferença entre a largura da praça e a da rodovia.

Assim, conforme McDonald \& Stammer (2001), as equações propostas são as equações (1) e (2) apresentadas a seguir: 


$$
\begin{aligned}
\text { Até } 70 \mathrm{~km} / \mathrm{h}: L & =\frac{W \cdot S^{2}}{290} \\
\text { Mais de } 70 \mathrm{~km} / \mathrm{h}: L & =0,23 \cdot W \cdot S
\end{aligned}
$$

em que L: comprimento mínimo da área de transição, em metros;

S: velocidade de aproximação, em quilômetros por hora;

W: offset da praça de pedágio, em metros.

\subsubsection{Zona de afastamento}

Analogamente à zona de aproximação, a área de transição da zona de afastamento é dividida em trechos da mesma forma que se divide a área de transição da zona de aproximação. $\mathrm{O}$ dimensionamento da zona de afastamento é análogo ao da zona de aproximação.

McDonald \& Stammer (2001) estabeleceram para a zona de afastamento uma diretriz similar à estabelecida para a zona de aproximação. Como o estudo realizado pelos autores não contemplava zonas de afastamento com altas velocidades, a formulação matemática se limitou à velocidade de 60 quilômetros por hora. Desta forma, o comprimento mínimo da área de transição é dado pela equação (3):

$$
L=1,5 \cdot \frac{W \cdot S^{2}}{290}+5 \cdot W
$$

em que L: comprimento mínimo da área de aceleração, em metros;

S: velocidade de regulamentada, em quilômetros por hora;

W: offset da praça de pedágio, em metros.

Schaufler (1997), tal qual na zona de aproximação, recomenda alguns valores apresentados na Tabela 5. A zona de afastamento começa com um trecho de largura constante (área de recuperação) e duas curvas reversas ligadas por um trecho em tangente, seguido por um trecho com um taper de 50:1 até o final da zona de aproximação. O autor recomenda que a área de recuperação possua um comprimento mínimo igual ao do veículo de projeto. 
Os valores para o taper da área de transição e para os raios da curva de concordância estão apresentados na Tabela 5 .

Tabela 5: Valores da zona de afastamento

\begin{tabular}{cccc}
\hline $\begin{array}{c}\text { Velocidade de } \\
\text { projeto }(\mathrm{km} / \mathrm{h})\end{array}$ & $\begin{array}{c}\text { Velocidade média de } \\
\text { viagem }(\mathrm{km} / \mathrm{h})\end{array}$ & $\begin{array}{c}\text { Comprimento mínimo da } \\
\text { zona de afastamento }(\mathrm{m})\end{array}$ & $\begin{array}{c}\text { Taper } \\
\text { máximo }\end{array}$ \\
\hline 80 & 70 & 223 & $4: 1$ \\
96 & 82 & 335 & $7: 1$ \\
112 & 93 & 457 & $10: 1$ \\
\hline \multicolumn{4}{c}{ Fonte: Schaufler (1997) }
\end{tabular}

\subsection{Cálculos do procedimento}

As áreas de transição - tanto na zona de aproximação, quanto na zona de afastamento - são divididas em um determinado número de trechos, como pode ser comprovado a seguir:

- Seja $\mathrm{N}_{\text {tran }}$ o número de transições, $\mathrm{N}_{\mathrm{p}}$ o número de faixas na praça e $\mathrm{N}_{\mathrm{r}}$ o número de faixas na rodovia.

- Na zona de aproximação, cada faixa em um trecho da área de transição se ramifica em duas no trecho seguinte.

- Desta forma, pode-se definir que $N_{r} \times 2 \times 2 \times \cdots \times 2 \times 2=N_{p}$, em que o número de faixas da rodovia será duplicado quantas vezes forem necessárias para que se atinja o número de faixas da praça. Com isso, $N_{r} \times 2^{N_{\text {tran }}}=N_{p}$.

- Isolando-se a variável $\mathrm{N}_{\text {tran }}$ e aplicando propriedades de logaritmos, conclui-se que o número de transições é definido pela equação (4):

$$
N_{\text {tran }}=\log _{2}\left(\frac{N_{p}}{N_{r}}\right)
$$

em que $\quad \mathrm{N}_{\text {tran }}=$ número de transições (arredondado para o inteiro acima);

$\mathrm{N}_{\mathrm{p}}=$ número de faixas na praça;

$\mathrm{N}_{\mathrm{r}}$ = número de faixas na rodovia a montante da praça. 
Os valores do taper propostos por Schaufler (1997) e por McDonald \& Stammer (2001) são bastante discrepantes, conforme apresentado na Figura 4 e na Figura 5, é preciso saber qual é o mais adequado.

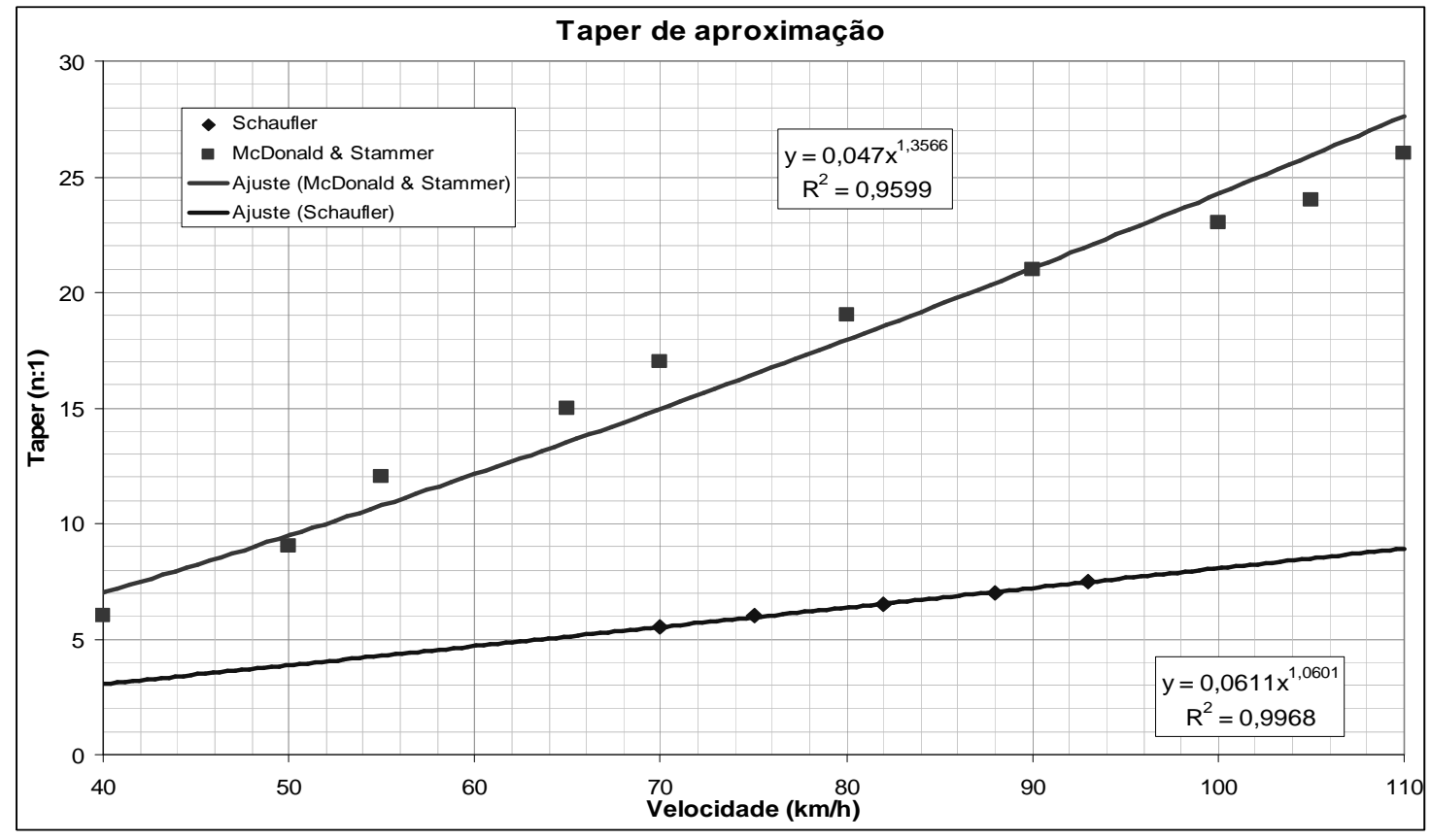

Figura 4: Comparação entre os valores do taper de aproximação. Fonte: Faria (2008)

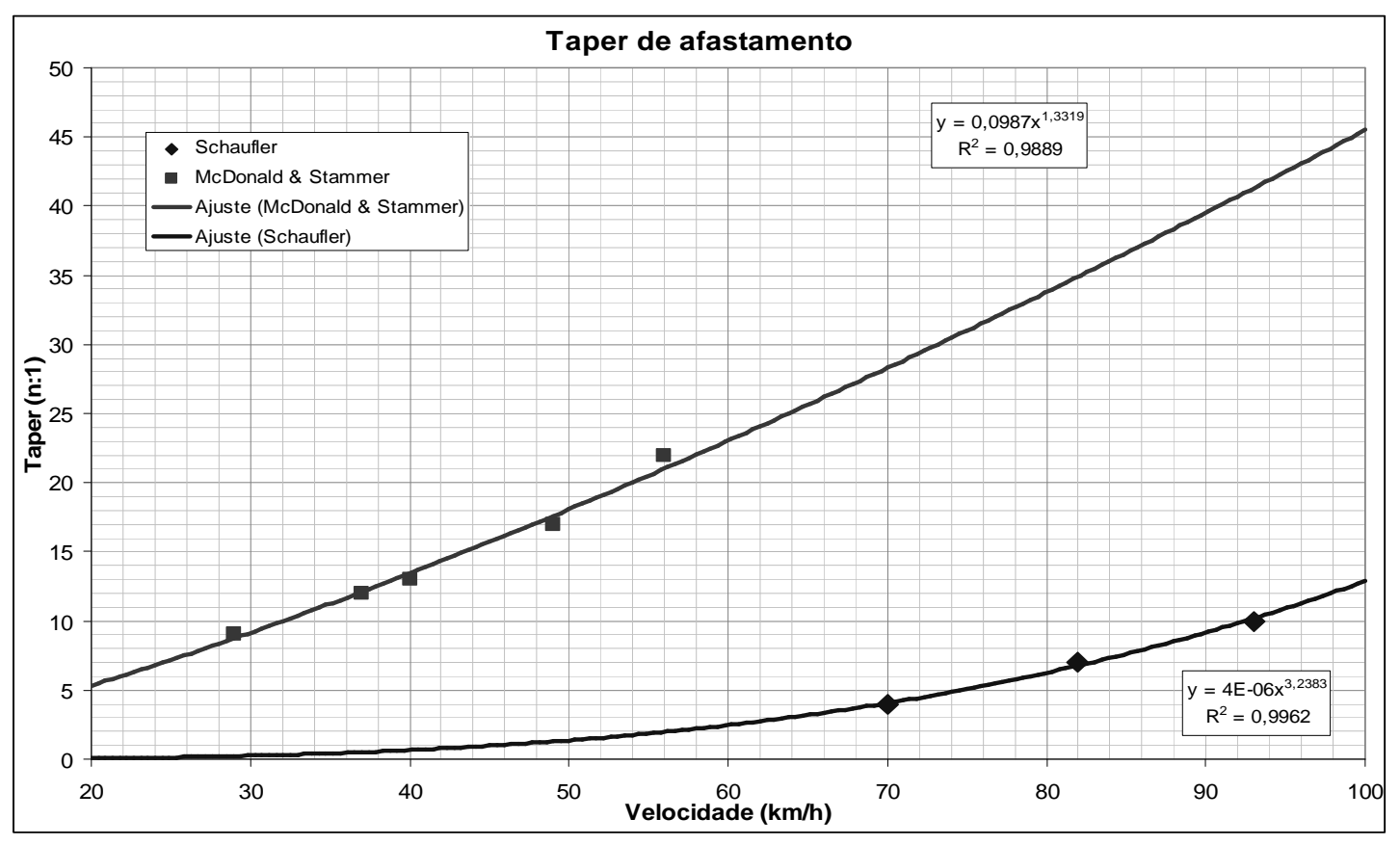

Figura 5: Comparação entre os valores do taper de afastamento Fonte: Faria (2008) 
Considerando-se uma velocidade média de $80 \mathrm{~km} / \mathrm{h}$ nas rodovias, percebe-se que uma solução razoável é utilizar uma curva que seja a média entre as curvas propostas pelos autores. Como se trata de análises empíricas, não é necessário fazer uma média ponderada, o que seria mais exato do ponto de vista matemático.

Na Tabela 6 é apresentado um quadro com o resumo de todas as equações necessárias para o dimensionamento dos elementos de layout.

Tabela 6: Equações para dimensionamento do layout

\begin{tabular}{|c|c|c|}
\hline \multirow{3}{*}{ Aproximação } & $\begin{array}{c}\text { Comprimento da área } \\
\text { de transição }\end{array}$ & $W \cdot V^{1,27} / 21,5$ \\
\hline & $\begin{array}{l}\text { Comprimento mínimo } \\
\text { da área de transição }\end{array}$ & $V^{2,17} / 72$ \\
\hline & $\begin{array}{l}\text { Comprimento da área } \\
\text { de filas* }\end{array}$ & $L_{\text {médio }} \cdot \frac{c \cdot r^{c+1}}{c ! \cdot(c-r)^{2}} \cdot\left[\sum_{n=0}^{c-1} \frac{r^{n}}{n !}+\frac{c \cdot r^{c}}{c ! \cdot(c-r)}\right]$ \\
\hline \multirow{2}{*}{ Afastamento } & $\begin{array}{c}\text { Comprimento da área } \\
\text { de recuperação }\end{array}$ & $1,2 \cdot V-32$ \\
\hline & $\begin{array}{c}\text { Comprimento da área } \\
\text { de transição }\end{array}$ & $W \cdot V^{1,57} / 47,5$ \\
\hline
\end{tabular}

Fonte: Faria (2008)

(*) Esta fórmula se aplica quando as chegadas seguem uma distribuição de Poisson e o atendimento segue uma distribuição exponencial.

Onde: $\quad \mathrm{W}=$ offset, em metros;

$\mathrm{V}=$ velocidade, em quilômetros por hora;

$\mathrm{c}=$ número de cabines;

$\mathrm{r}=$ número de clientes em serviço no estado de equilíbrio $(r=\lambda / \mu)$;

$\mathrm{L}_{\text {médio }}=$ comprimento médio de um veículo 


\section{Protótipo computacional e exemplo de aplicação}

Para facilitar o processo de análise foi desenvolvido um programa computacional para o cálculo dos elementos de layout de uma praça de pedágio baseado no procedimento proposto. Este protótipo computacional foi desenvolvido em linguagem MATLAB. O programa é composto de duas partes. A primeira parte executa uma análise de cenários variando-se a porcentagem de veículos de passeio e a porcentagem de veículos que efetuam pagamento manual. Com isso, o programa exibe a variação das quantidades de cabines manuais e de cabines eletrônicas de acordo com cada situação. A utilização do programa é bastante intuitiva.

Na segunda parte, o programa calcula os elementos de layout. Tal qual a primeira parte, a interface, apesar de não ser amigável, é bastante simples para a introdução dos dados de entrada.

Os dados de entrada são:

- Fila média e tempo médio de espera;

- Fluxo de tráfego na hora de pico ;

- Porcentagem de veículos pesados e leves.

- Porcentagem de usuários de pagamentos eletrônicos e manuais;

- Número de faixas na rodovia antes e depois da Praça;

- Largura de faixa na rodovia antes e depois da Praça;

- Velocidade de aproximação na praça;

- Taxas de serviço manual e eletrônica.

- Largura da faixa de pedágio e largura da ilha.

O programa computacional permite simular cenários para diferentes configurações de pedágios e indica a melhor situação. A Figura 5 apresenta uma tela com um arquivo de dados de entrada e a Figura 6 mostra o resultado de um estudo de caso em que se deseja uma configuração para o nível de serviço D. 


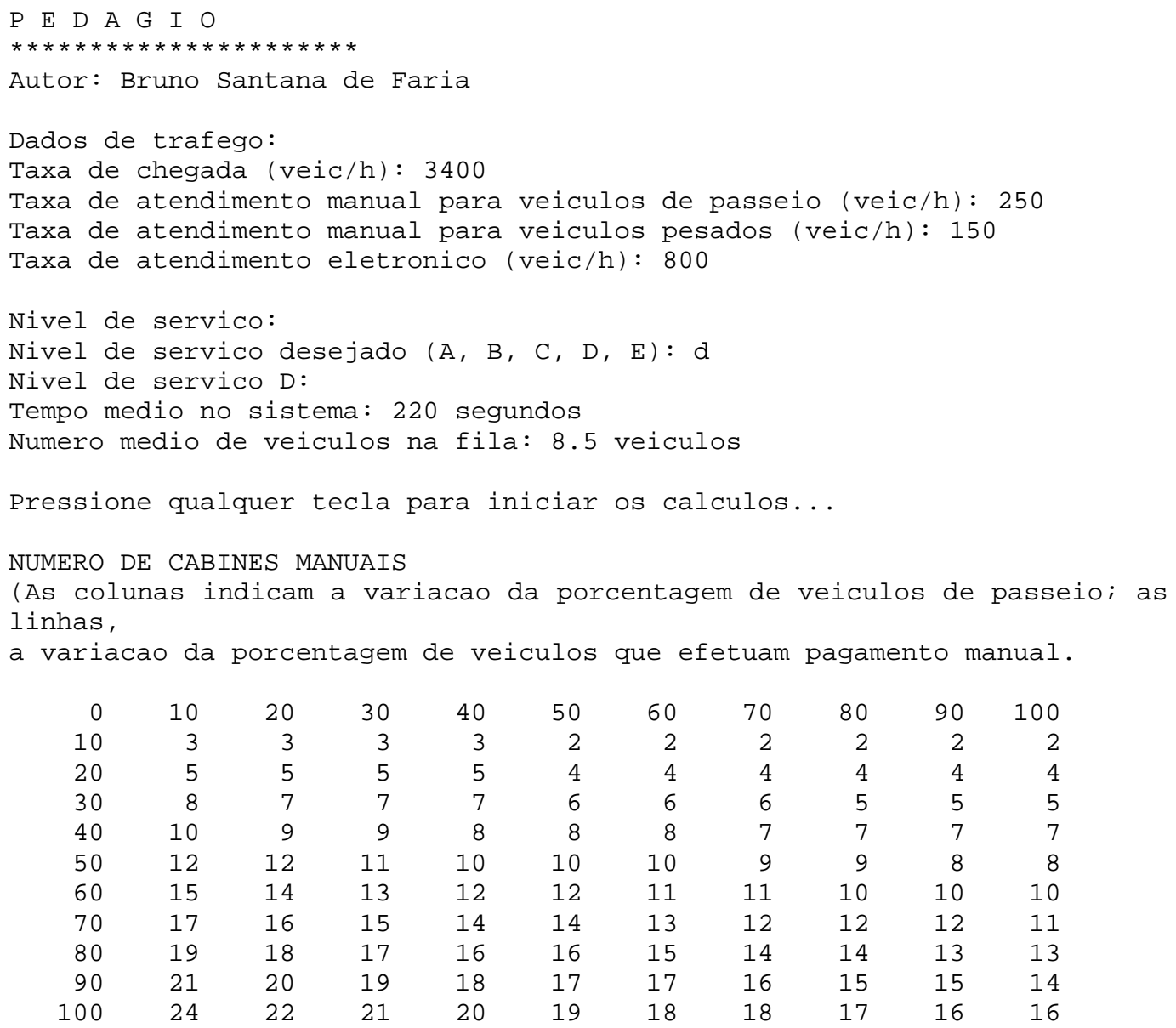

$\begin{array}{rrrrrrrrrrr}0 & 10 & 20 & 30 & 40 & 50 & 60 & 70 & 80 & 90 & 100 \\ 10 & 3 & 3 & 3 & 3 & 2 & 2 & 2 & 2 & 2 & 2 \\ 20 & 5 & 5 & 5 & 5 & 4 & 4 & 4 & 4 & 4 & 4 \\ 30 & 8 & 7 & 7 & 7 & 6 & 6 & 6 & 5 & 5 & 5 \\ 40 & 10 & 9 & 9 & 8 & 8 & 8 & 7 & 7 & 7 & 7 \\ 50 & 12 & 12 & 11 & 10 & 10 & 10 & 9 & 9 & 8 & 8 \\ 60 & 15 & 14 & 13 & 12 & 12 & 11 & 11 & 10 & 10 & 10 \\ 70 & 17 & 16 & 15 & 14 & 14 & 13 & 12 & 12 & 12 & 11 \\ 80 & 19 & 18 & 17 & 16 & 16 & 15 & 14 & 14 & 13 & 13 \\ 90 & 21 & 20 & 19 & 18 & 17 & 17 & 16 & 15 & 15 & 14 \\ 100 & 24 & 22 & 21 & 20 & 19 & 18 & 18 & 17 & 16 & 16\end{array}$

Pressione qualquer tecla para continuar...

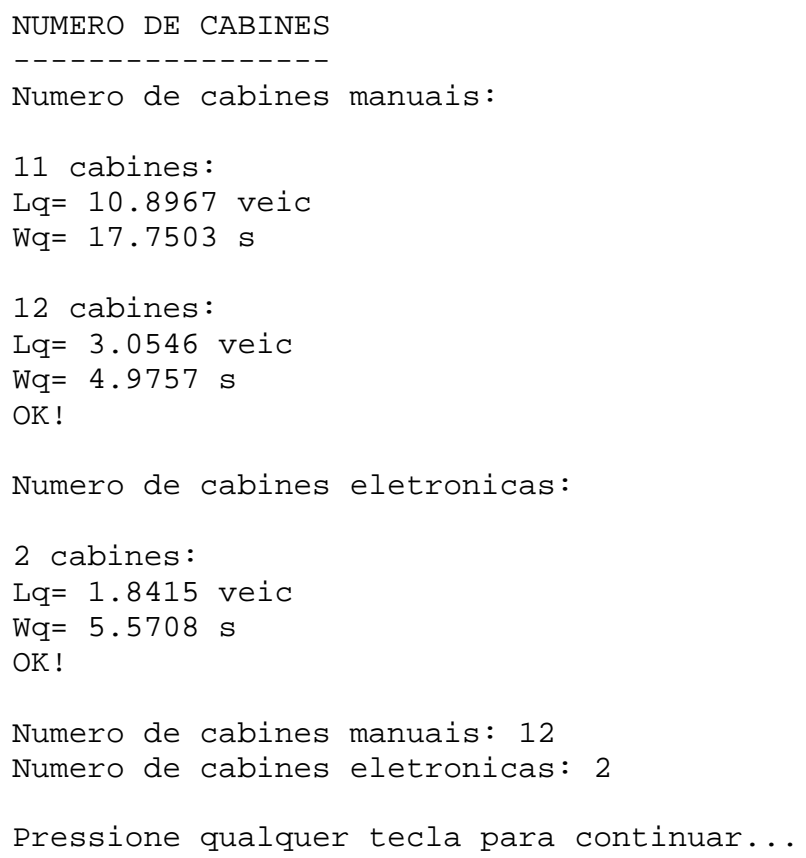

Figura 6 - Parte da tela com alguns resultados da análise 


\section{Conclusões}

No estudo realizado, foram identificados alguns fatores que têm influência direta sobre o dimensionamento do layout:

- O número de cabines é proporcional à quantidade de veículos que trafega na rodovia. Para as cabines manuais, quanto maior for a porcentagem de veículos que efetuam pagamento manual, maior será o número de cabines para que se atinja um determinado nível de serviço. Também será maior quanto maior for a porcentagem de veículos pesados, devido ao maior tempo necessário para o atendimento.

- O comprimento da área de transição da zona de aproximação (e também da zona de afastamento) aumenta em função da velocidade e do padrão de alargamento (e de encurtamento) adotado. Para alargamentos para a esquerda, ou para a direita, o comprimento das áreas de transição são maiores que os mesmos utilizando-se um padrão de alargamento centralizado. O fluxo exerce influência no dimensionamento, já que o offset é função do número de cabines que, por sua vez, é função, dentre outros fatores, do fluxo no horário de pico.

- A área de filas, dependendo do nível de serviço desejado, pode estar superdimensionada, já que em algumas situações o comprimento necessário é menor que o mínimo estipulado pelo procedimento.

A identificação destes fatores se fez a partir de um estudo de vários procedimentos realizados por Schaufler (1997) e McDonald \& Stammer (2001) no que diz respeito ao dimensionamento do layout, e por Tiefensee (2005) no dimensionamento do número de cabines.

A falta de dados reais impossibilitou uma comparação aprofundada que pudesse validar o procedimento. Foi enviado um questionário às 36 concessionárias de rodovias em operação no país. Infelizmente, nenhuma respondeu as perguntas relativas aos elementos de layout.

Dada a complexidade do assunto, o procedimento tem por limitações as seguintes características que podem ser posteriormente analisadas:

- Não se consideram cabines reversíveis na praça. 
- A rodovia possui mais de uma faixa por sentido. Isso é uma informação importante, já que em rodovias de uma faixa podem ser formados "pelotões" atrás de veículos lentos. Esse fenômeno tende a ocorrer em trechos montanhosos da rodovia.

- Não há limitação transversal quanto à largura da praça.

- Não são utilizadas cabines em tandem ou cabines ramificadas. Essas limitações se dão somente pelo fato de não terem sido estudadas essas peculiaridades possíveis a uma praça de pedágio.

\section{Referências}

ABCR - Associação Brasileira de Concessões de Rodovias (2007) Relatório Anual 2006. Disponível em <http://www.abcr.org.br/download/relatABCR2005.pdf〉. Visualizado em 18 Nov, 2007.

ANTT - Agência Nacional de Transportes Terrestres (2006a) Concessões rodoviárias - apresentação. Disponível em <http://www.antt.gov.br/concessaorod/apresentacaorod.asp>. Visualizado em 12 Nov, 2006.

ANTT - Agência Nacional de Transportes Terrestres (2006b) Concessões rodoviárias: $2^{a}$ etapa apresentação. Disponível em <http://www.antt.gov.br/relatorios/rodoviario/Novasconcessoes2. ppt>. Visualizado em 26 Nov, 2006.

Araújo, J. J. (2001) Características operacionais de praças de arrecadação de pedágio. Dissertação (Mestrado). Escola de Engenharia de São Carlos, Universidade de São Paulo. São Carlos.

BNDES - Banco Nacional de Desenvolvimento Econômico e Social (2007) BR-116/324 - Parceria público-privada: o projeto. Disponível em <http://www.pppbr116.org/projeto .html>.Visualizado em 25/10/ 2007.

Consumidor Brasil (2007) Pedágio. Disponível em <http://www.consumidorbrasil.com.br/ consumidorbrasil/textos/dicasconsumo/pedagio.htm>. Visualizado em 26 Out, 2007.

Faria, B. S. (2008) Procedimento para dimensionamento do layout de praças de pedágio. Dissertação (Mestrado). Instituto Militar de Engenharia. Rio de Janeiro.

Klodzinski, J.; Al-Deek, H. M. (2002) Proposed Level of Service Methodology for Toll Plazas. 81st Transportation Research Board Annual Meeting. National Research Council, Washington, EUA.

McDonald, D. R.; Stammer, R. E. (2001) Contribution to the development of guidelines for toll plaza design. Journal of Transportation Engineering, Vol 127, No. 3.

Oliveira, M. L; Rosa Neto, J. M.; Cybis, H. B. B. (2003) A Influencia do tamanho das filas na capacidade de Atendimento das praças de pedágio. Anais do XVII ANPET - Congresso Brasileiro de Pesquisa e Ensino em Transportes. Rio de Janeiro.

Oliveira, M. L (2009), Método para determinação de Nível de serviço em Praças de pedágio. Tese (doutorado), Programa de Engenharia de Produção, UFRGS, Porto Alegre.

Rastorfer, R. L. (2004) Toll plaza concepts. ASCE Fall Conference, Houston, EUA. 
Schaufler, A. E. (1997) Toll Plaza Design. NCHRP Synthesis of Highway Practice 240. Transportation Research Board, National Research Council. Washington, EUA.

Smith, R. F. (2006) State of practice and recommendations on traffic control strategies at toll plazas. U.S. Department of Transportation - Federal Highway Administration.

Tiefensee, M. D. (2005) Dimensionamento de cabines de cobrança em praças de pedágio. Dissertação (Mestrado). Universidade Federal do Rio Grande do Sul. Porto Alegre. 